\title{
OPTIMIZATION OF MEDIA PLANNING VARIABLES FOR TELEVISION BASED ON THE ADVERTISER'S INDUSTRY
}

\author{
Pedro Reinares-Lara, Josefa D. Martín-Santana, Eva Reinares-Lara
}

\section{Introduction}

The market research institutes that measure the impact of advertising campaigns aggregate their results according to different criteria in order to provide clients with a normative framework or framework of reference. In addition to the volume of advertising investment, one of the most common criteria is the industry or product category, due to its influence on effectiveness measures. The academic literature has likewise underscored the need to take into account a product category when assessing advertising effectiveness (Vakratsas \& Ambler, 1999).

The concepts of industry and product category have drawn attention from researchers because of their usefulness in defining business strategies. For example, the interest in dividing markets into subgroups based on industries and product categories is grounded in the possibility of conducting a more comprehensive and accurate analysis of the competition and competitive advantages. In implementing their positioning strategies, companies often assume that consumers have some knowledge of the structure and specific attributes of the product category and that they can use this knowledge when choosing a brand (Chattopadhyay, Nedungadi, \& Muthukrishnan, 2001).

In this context, from an advertising perspective, different criteria can be used to group advertisers into more or less broad categories in order to justify a campaign's effectiveness. Thus, it is possible to establish standard levels for effectiveness measures for advertisers from a single industry or product category in order to allow them to assess the effectiveness of their campaigns in relation to those of other advertisers from their industry or category. This business practice is based on the belief that advertising effectiveness results cannot be generalized to all product categories (Youn, Wells, \& Zhao, 2001). In this regard, meta-analyses of the effects of advertising have identified the characteristics of a specific industry or product as explanatory factors for differences in advertising effectiveness (Assmus, Farley, \& Lehmann, 1984; Sethuraman \& Tellis, 1991).

In addition to the industry, to ensure a campaign's effectiveness, advertising agents must take into account not only the quality of their advertisements, but also a number of creative strategies related to media planning (Jeong, Tran, \& Zhao, 2012). To this end, management of media planning variables must be improved due to the direct influence of these variables on recall (Soberman, 2005), a widely used measure in research on advertising effectiveness (Jeong, Kim, \& Zhao, 2011; McDonald, 2000; Romaniuk, Sharp, Paech, \& Driesener, 2004).

Despite evidence that the product category to which a brand belongs influences the recall generated by its advertising campaigns, few academic papers have sought to explain in detail why the recall generated by equivalent media plans varies depending on the industry to which the brand belongs. Some have argued that advertisers need to improve their strategic planning in order to identify the variables that moderate advertising effectiveness depending on the product category (Nyilasy \& Reid, 2009). Identifying the determinants of the differences in television advertising recall across industries and product categories has important implications for brand management (Christensen \& Hansen, 2005; Willke, 1993). For advertisers, knowing early on in the media planning decision-making process whether the industry to which their brand belongs generates more or less recall than other industries provides a new criterion that can be used to optimize media plans requiring the use of television (Media Dynamics, 2006).

In light of this background, this paper primarily aims to analyze the direct influence 
of an advertised brand's industry on unaided advertising recall. Since the ultimate effectiveness of an advertisement depends on the interaction of a set of variables related to advertising planning, the advertised product, and the individual, rather than on the individual effect of any one of these variables alone, this paper will also explore the moderating effect of the advertised brand's industry on the relationship between recall and the following media planning variables: (1) spot length, (2) advertising pressure of the brand, (3) the position of the commercial break in relation to the program, (4) advertising clutter of the break, (5) indication of the break's duration, (6) the spot's relative position within the break, and (7) primacy and recency effects. Although several studies have addressed the effects of each of the main planning variables individually, the primary contribution of this paper is to analyze the relationship between advertising recall and media planning variables from a holistic perspective. Achieving these aims will enable the proposal of a series of recommendations for optimizing television media planning depending on the advertiser's industry and will provide the necessary empirical proof to advance knowledge.

The research was carried out in a real environment due to the wider acceptance of such environments in the advertising industry for overcoming limitations related to the reliability of the results of laboratory tests (Hu, Lodish, \& Krieger, 2007; Moorman, Neijens, \& Smit, 2007; Pieters \& Bijmolt, 1997; Zhao, 1997). This decision required the integration of two information sources to adjust the recall levels to the actual audience: an audience panel organized by Kantar Media and computer-assisted telephone interviewing (CATI). Our study was conducted in Spain, although in the theoretical framework used in the formulation of our research proposition we have also considered other geographical areas when these were relevant and could be extrapolated to our aims.

\section{Industry and Advertising Recall}

Advertising recall reflects an advertisement's ability to generate attention and grab the audience's interest (Ross, 1982). Compared to other measures of recall, it stands out for its objectiveness and reliability (Wells, 2000). Among the different measures of recall, verified unaided recall measures an advertisement's ability to spontaneously leave a mark on an individual's mind, thereby making it possible to avoid potential distortions caused by previous campaigns the individual might recall during the data-collecting process (Beerli \& Martín, 1999).

Several academic studies have explored the influence of industry or product type on advertising recall (Ewing, Napoli, \& Du Plessis, 1999; Li, 2010; Media Dynamics, 2006; Stewart \& Furse, 1985; Sujan \& Dekleva, 1987; Youn et al., 2001). This literature includes studies analyzing the effectiveness of various product categories according to different product grouping criteria. However, this disparity of criteria hinders the direct comparison of the results of the different studies (Sujan \& Dekleva, 1987). Thus, average unaided brand recall varies from $15.5 \%$ in the automobile industry to $27.9 \%$ in the food industry (Media Dynamics, 2006). Looking at the correlation between 12 product categories and recall, Stewart and Furst (1985) found that the latter ranged from 5 to $80 \%$. Likewise, Youn et al. (2001) found that the unaided and aided recall levels achieved for the three main product categories they establish (approach, avoidance, and utilitarian) had very broad ranges, of 0 to $54.86 \%$ and 7.62 to $75.95 \%$, respectively.

The difference in recall levels in different industries or product categories is probably due to the combined, integrative effect of multiple variables related to advertising planning (Fig. 1), including media and creative strategy, the advertised product, and individual viewer characteristics (Beerli \& Martín, 1999; Stewart \& Koslow, 1989; Stewart \& Furse, 1985).

With regard to the variables related to media strategy, the literature includes studies highlighting the influence of the following variables on recall:

Spot length: defined as a commercial's duration in seconds (Alba \& Chattopadhyay, 1986). There is a consensus in the literature on the ability of longer commercials to grab viewers' attention, improve learning, and be processed (Newell \& Henderson, 1998; Rossiter \& Bellman, 2005; Singh \& Cole, 1993), and, therefore, to achieve higher levels of recall (Alba \& Chattopadhyay, 1986; Ewing et al., 1999; Mord \& Gilson, 1985; Newstead \& Romaniuk, 2009; Patzer, 1991; Pieters \& Bijmolt, 1997; Rossiter \& Bellman, 2005; Young, 2008).

Advertising pressure of the brand: The recall generated by an advertising campaign endures 


\section{Fig. 1: Factors influencing advertising recall}

\section{Related to advertising planning}

Media strategy:

- Types of media and formats used

- Advertising pressure put behind the brand

- Advertising pressure of the industry/product category

- Duration and intensity of the campaign

- Length or size, format, and position of the advertisement within the break

- Characteristics of the commercial break

Creative strategy:

- Creativity

- Content of the advertisement

\section{Related to the advertised product}

- Industry

- Product type

- Brand awareness

- Brand image

\section{Related to the individual}

- Sociodemographic characteristics

- Brand knowledge

- Attitude toward the brand

- Experience with the brand

- Degree of engagement with the product

- Attitude toward advertising and advertising media

over time (Naik, Mantrala, \& Sawyer, 1998). It is thus impossible to isolate the recall generated by a specific campaign, as it is the result of the brand's advertising pressure over a period including multiple campaigns. This variable is quantified as the total number of GRPs a brand has broadcast on television in a given period. The advantage of this quantification, as opposed to the number of spots broadcast or the brand's total investment in a given period, is that these alternative measurements fail to take into account variations both in the audience actually reached by each spot, depending on its distribution in the media plan, and in advertising costs, which depend on the advertiser's bargaining power with the media outlet. The literature on the effect of advertising pressure in television widely assumes that recall increases with the number of GRPs achieved by a brand's campaigns in a given period (Draganska, Hartmann, \& Stanglein, 2014). However, the effect of this recall has also been shown to decrease once certain maximum levels have been reached, such that numerous studies recommend optimizing campaign recall by establishing a level of advertising pressure that does not exceed the number of exposures needed to generate the maximum level of recall (Wild, 1996). While the advertising pressure of a brand affects recall, this relationship is also affected by other factors, such as campaign creativity or the newness of the brand (Danaher \& Rust, 1994; Van den Putte, 2009).

Position of the commercial break in relation to the program: In the planning of an advertising campaign, whether to show a spot in a commercial break between programs or in a mid-program break is a key decision due to the collateral effects of the audience's engagement with the program. It is generally assumed that the higher the audience's engagement with the program in which a spot is placed, the greater the recall (Lloyd \& Clancy, 1991; Moorman, Willemsen, Neijens, \& Smit, 2012). Therefore, since audience engagement with a program declines once it is over, the effects on recall are higher in mid-program commercial breaks than in breaks positioned between programs (Chowdhury, Finn, \& Olsen, 2007; Krugman, 1983; Moorman et al., 2007). 
Advertising clutter of the break: usually defined as the number of advertisements in a given period or on a given medium ( $\mathrm{Ha} \&$ McCann, 2008; Riebe \& Dawes, 2006), whereby the greater the clutter, the lower the advertising recall (Brown \& Rothschild, 1993; Ha \& McCann, 2008; Pieters \& Bijmolt, 1997). This negative effect on recall is because greater advertising clutter leads to less attention due to the irritation and confusion it causes (Ha \& McCann, 2008; Jeong et al., 2011), as well as to individuals' limited memory capacity (Ha \& McCann, 2008).

Indication of the duration of the commercial break: One strategy that television networks use to prevent zapping during commercial breaks is to indicate the duration of the break to their audiences. Some studies have shown that advertisement recall is higher when networks expressly indicate the duration of a break (Smith, 1986; Yu, Chan, Zhao, \& Gao, 2012), as it can reduce the anxiety caused by not knowing exactly how long the break will last (Rachman, 1998), as well as the unpleasantness and discomfort created by this uncertainty (Bensi \& Giusberti, 2007).

Relative position of the spot within the commercial break: The interest of this variable lies in the belief that spot recall can be explained, first, by ordinal variables (the spot's position in the break, usually measured in terms of the primacy effect) and, second, by the level of advertising clutter surrounding the spot (measured by the duration of the break in which it has been placed). A spot's positioning in relation to the total duration of the commercial break can affect recall, which decreases the further away the spot is placed from the program, i.e., when it is shown in the middle positions of the break (Pieters \& Bijmolt, 1997; Nielsen Media Research \& Cable Television Advertising Bureau, 2000; Terry, 2005). This negative influence on recall is more explicit in long breaks (Li, 2010).

Primacy and recency effects: Various studies have shown that advertising products in the first and last slots of a commercial break generates greater recall (Brunel \& Nelson, 2003; Burke \& Srull, 1988; Pieters \& Bijmolt, 1997), a phenomenon known as the primacy and recency effect. However, unlike the primacy effect, some studies have failed to corroborate the recency effect (Li, 2010; Newell \& Wu, 2003; Webb \& Ray, 1979; Zhao, 1997). Swaminathan and Kent (2013) found that the prevalence of the recency effect over the primacy effect is greater with longer commercial breaks and depends on the impact of the program scheduled to begin or resume when the break ends.

A review of the literature shows that little attention has been given to testing the potential moderating effect of the analyzed planning variables on recall results, although in the discussions of their findings, some authors have mentioned the possible moderating effects of other variables (Yu et al., 2012) and the need to study them (Jeong et al., 2011; Norris, Colman, \& Aleixo, 2003). Most of the identified papers focus on the moderating role of variables related to the product or brand or to the individual, such as individuals' engagement with the product, product knowledge, or familiarity with the brand, as well as their interest in the program in which the break containing the advertisement is inserted or in the program directly preceding or following it. Thus, with regard to the moderating role of the media planning variables analyzed in the present paper, only spot length has been analyzed and shown to exert a moderating influence on the effects on recall of a brand's advertising pressure (MartínSantana, Reinares-Lara, \& Reinares-Lara, 2016), the advertising clutter of a break (Martín et al., 2016; Mord \& Gilson, 1985; Pieters \& Bijmolt, 1997; Ward et al., 1989), a spot's relative position within the break (Ward, Reibstein, Oliva, \& Taylor, 1989), and the recency effect (Martín et al., 2016; Pieters \& Bijmolt, 1997). Likewise, only Pieters and Bijmolt (1997) and Li (2010) have shown the moderating effect of the clutter of a commercial break on the influence exerted on recall by a spot's relative position within the break. In contrast, no relevant papers were found analyzing the moderating role of industry or product category. However, due to the existence of contradictory findings in some cases, the following research proposition (RP) was proposed to test the interaction effects of industry with the analyzed media planning variables:

$R P$ : Industry plays a moderating role in the optimization of media planning variables.

\section{Methodology}

\subsection{Methodological Design}

This study used an innovative methodology that made it possible to measure spot recall in an environment that had been absolutely adjusted to the real conditions of a television audience. This methodological contribution stems from the fact that the recall rates obtained by conducting 
surveys do not consider an advertisement's effect in terms of real audience levels, but rather based on the defined sample size. Thus, the advertising recall rates obtained do not reflect the spot's real impact, since, for instance, if a spot obtains a recall level of $10 \%$ based on a survey, its actual recall level will be different depending on the real audience of the commercial break in which it was shown. Therefore, if the actual audience level were $80 \%$, a recall level of $10 \%$ would imply a smaller real impact on the audience than if the actual audience level were $20 \%$. By applying the proposed methodology, this study aimed to obtain recall levels adjusted to the real audience of each spot. To this end, two sources of information that are usually used independently were combined: (1) audience data provided by the firm Kantar Media; and (2) data from ad-hoc computer-assisted telephone interviews (CATIs) designed to gather information on advertising recall. These data were integrated to obtain a weighting coefficient for each spot, calculated as the quotient of the percentage of unaided recall obtained through the television survey and the audience share of the commercial break in which the spot was broadcast. It was thus possible to adjust recall levels to the real audience figures by multiplying the weighting coefficient by 1 or 0 , depending on whether or not the respondent recalled the spot. As a result, unaided recall ceased to be a dichotomous variable and became a continuous one, which, in the present study, ranged from 0 to 3.98 .

The information needed to conduct this research was gathered over two consecutive months (May-June 2014), and real brand/ product recall levels (e.g., Ford Focus C-Max) were obtained for all spots broadcast over this period on all national, generalist, free-to-air channels in Spain. This involved measuring recall for 1,196 spots identified by industry and brand, encompassing a total of 21 industries and 400 brands. However, for this paper in particular, only five industries were selected, corresponding, in accordance with the Infoadex classification, to: "Food," "Automotive," "Health and Beauty," "Financial and Insurance," and "Telecommunications and Internet." In keeping with the objectives of the present research, the use of the Infoadex industry classification ensured that the results could be compared between industries at the national level, as the categories it establishes are widely accepted and used in advertising (Pergelova, Prior, \& Rialp, 2010). These five industries were chosen in accordance with the following criteria, in light of the data contained in the 2014 Infoadex report: (1) investment in television advertising in excess of 100 million euros; (2) they are topranked in terms of investment, accounting for $59.8 \%$ of all investment in television; and (3) homogeneity of the product categories included in the industry to prevent them from influencing the results. Once the five industries had been chosen, 273 spots representing a total of 176 different brands were analyzed.

Unaided recall of the spots broadcast during the period under consideration was measured using an ad-hoc structured questionnaire administered by CATI to a sample of 2,000 individuals. Respondents were recruited two days prior to the broadcasting of the programs by means of random digit dialing. All respondents agreed to be interviewed at a specific time while they were watching television at home. Quotas were established for gender, age, household size, and town size in order to obtain a reliable and representative sample of the Spanish television audience aged 16 to 65 (see Tab. 1).

The questionnaire was automatically adapted to each interview by the call center's computer system to reflect the specific break

\section{Tab. 1: Sample distribution}

\begin{tabular}{l|c|c|c|l|c}
\multicolumn{1}{c|}{ Gender } & $\%$ & Age & $\%$ & \multicolumn{1}{|c}{ Household size } & $\%$ \\
\hline Male & 39.2 & $16-19$ & 12.9 & One-member household & 16.7 \\
\hline Female & 60.8 & $20-24$ & 10.9 & 2-to-3-member household & 32.6 \\
\hline & & $25-34$ & 15.4 & 4-to-7-member household & 41.5 \\
\hline & & $35-44$ & 18.3 & 8 or more household members & 9.2 \\
\hline & & $45-65$ & 42.5 & & \\
\hline
\end{tabular}




\section{Marketing and Trade}

and/or spot. The elements included in each interview were: channel, time, position of the commercial break, and brands and/or products for which spots were broadcast during the tested time period. The interview was a maximum of 4 minutes long. All respondents were asked about the programs they had watched during the 30 minutes prior to the call (as a control mechanism) and about the spots broadcast in the 15 minutes prior to the time period in which the interview was conducted. Tab. 2 summarizes the methodological procedure followed for the completion of the questionnaires.

Once the fieldwork had been completed, the individual respondents' files were converted into a single file with 36,362 observations

\section{Tab. 2: Technical details of the research}

\begin{tabular}{l|l} 
Universe & $\begin{array}{l}\text { Individuals aged } 16 \text { to } 65, \text { representative of the total Spanish } \\
\text { television audience }\end{array}$ \\
\hline Sample location & Spain \\
\hline Data-gathering method & $\begin{array}{l}\text { Personal survey through a structured questionnaire administered by } \\
\text { phone (CATI) }\end{array}$ \\
\hline Sample size & 2,000 interviews \\
\hline Sample error & $\pm 4 \%$ \\
\hline Confidence interval & $95 \% \mathrm{Z}=1.96$ \\
\hline Sampling procedure & Stratified (gender, age, household size, and town size) \\
\hline Maximum allowed variance & $\mathrm{p}=\mathrm{q}=50 \%$
\end{tabular}

\section{Tab. 3: Study variables}

\begin{tabular}{|c|c|}
\hline Variable & Status \\
\hline Spot length & $\begin{array}{l}\text { 1. Less than } 20 \text { seconds } \\
\text { 2. } 20 \text { seconds } \\
\text { 3. } \text { More than } 20 \text { seconds }\end{array}$ \\
\hline Advertising pressure of the brand & $\begin{array}{l}\text { 1. High pressure (the television advertising pressure of the } \\
\text { brand featured in the spot is } 200 \% \text { higher than that of } \\
\text { the other brands being analyzed) } \\
\text { 2. Low pressure }\end{array}$ \\
\hline $\begin{array}{l}\text { Position of the commercial break in } \\
\text { relation to the program }\end{array}$ & $\begin{array}{l}\text { 1. Between programs } \\
\text { 2. Mid-program } \\
\end{array}$ \\
\hline Advertising clutter of the break & $\begin{array}{l}\text { 1. Break with low advertising clutter (1 to } 23 \text { spots) } \\
\text { 2. Break with medium advertising clutter ( } 24 \text { to } 43 \text { spots) } \\
\text { 3. Break with high advertising clutter ( } 44 \text { to } 49 \text { spots) }\end{array}$ \\
\hline Indication of the duration of the break & $\begin{array}{l}\text { 1. Normal } \\
\text { 2. We'll be back in... }\end{array}$ \\
\hline $\begin{array}{l}\text { Relative position of the spot within } \\
\text { the break (quotient of the time from } \\
\text { the break's start in seconds and the } \\
\text { break's total duration in seconds) }\end{array}$ & $\begin{array}{l}\text { 1. Early relative position } \\
\text { 2. Middle relative position } \\
\text { 3. Late relative position }\end{array}$ \\
\hline Primacy & $\begin{array}{l}\text { 1. Primacy (first position) } \\
\text { 2. Other }\end{array}$ \\
\hline Recency & $\begin{array}{l}\text { 1. Recency (last position) } \\
\text { 2. Other }\end{array}$ \\
\hline
\end{tabular}


(each spot evaluated by a respondent became a separate record), of which a total of 19,428 were related to the five industries being considered. Therefore, if a respondent had seen 20 spots, it would translate to one interview with 20 different respondent-spot records. In this study, the unaided recall rate for the five studied industries was $0.63 \%$ of the total of 19,428 observations.

\subsection{Study Variables}

The questionnaire consisted of two blocks. The first block, which was conducted in the preliminary respondent recruitment phase, gathered socio-economic data and information on viewing habits. The second block contained questions related to unaided recall, in which respondents also had to indicate the program and/or network watched. This information was used to obtain adjusted recall levels for each spot. Separately, the audience levels for each commercial, along with the variables included in Tab. 3, were extracted from the Kantar Media audience study.

\section{Results}

Prior to the combined analysis of how all the factors involved in the planning of the commercial break affected unaided recall, an individual ANOVA analysis was conducted for each of the eight factors, both in overall terms and for each of the five industries considered. The results (Tab. 4) showed that, overall, all the variables under consideration influenced unaided recall of the spot, as supported by the literature. It can thus be derived that higher levels of unaided recall are generated when spot length is increased, when the advertising pressure of a brand is high, when a spot is shown in a mid-program break, when a spot is shown in a low-clutter break, when it is shown relatively early or late in the break, when it comes first or, especially, last in the break, and, finally, when the audience is told the duration of the commercial break. In contrast, the industryspecific analyses yielded different results, as not all the variables influenced unaided recall. Thus, for example, in the "Automotive" industry, the maximum unaided recall was achieved when the spot was shown between programs, when it came first or, especially, last in the break, and, finally, when the audience was told the break's duration. These results thus show that industry is a factor that should be taken into consideration in the planning of campaigns and that, therefore, the same premises cannot be used for all industries.

In order to analyze the combined effect of all the planning variables on unaided recall, since, in practice, they act together, a univariate analysis of variance for multiple factors was performed, in which the dependent variable was unaided recall and the fixed or independent variables were the eight planning variables analyzed in this paper. The results, shown in Tab. 5, both overall and for each of the five industries, again corroborated the possible moderating role of industry insofar as the results for each industry were not the same. Thus, for example, in the "Automotive" industry, indicating the length of the commercial break to the audience and showing the spot last in the break were found to be decisive factors for the level of unaided recall, whereas, in the Financial and Insurance" industry, spot length and brand awareness were key.

In order to determine the moderating role of industry, a univariate analysis of variance for multiple factors was performed, in which the dependent variable was again unaided recall and the fixed or independent variables were the eight planning variables analyzed in this paper, as well as the industry and its interaction with each of the eight planning variables. As can be seen from the ANOVA results (Tab. 6), industry had a very significant influence on unaided recall levels $(F=10.815, p=0.000)$. Spot length, advertising pressure of the brand, the position of the commercial break in relation to the program, and recency were also found to influence unaided recall. With regard to the interaction effects of industry, the results also showed that it moderates the influence on unaided recall of spot length, the brand's advertising pressure, the advertising clutter of the break, indication of the duration of the break, and recency. This finding, therefore, supports the initial research proposition, namely, that industry plays a moderating role in the optimization of media planning variables.

Given the importance of industry in media planning, it was considered to be of interest for business practice to determine, overall and for each industry, the exact changes in the levels of unaided recall. To this end, indices were used with a base score of 100 , representing the average value for overall unaided recall, which stood at 0.0057 . Tab. 4 shows the calculations 


\section{Marketing and Trade}

Tab. 4:

Mean values and unaided recall rate depending on the product category, overall and for each planning variable

\begin{tabular}{|c|c|c|c|c|c|c|c|c|c|c|c|c|c|c|c|c|c|c|c|c|}
\hline & \multicolumn{3}{|c|}{ 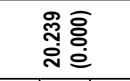 } & \multicolumn{2}{|c|}{ ¿ } & \multicolumn{2}{|c|}{ 尊高 } & \multicolumn{3}{|c|}{ 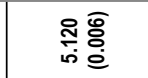 } & \multicolumn{2}{|c|}{ 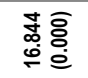 } & \multicolumn{3}{|c|}{ 芯 } & \multicolumn{2}{|c|}{ 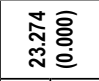 } & \multicolumn{2}{|c|}{ 总 } & \\
\hline & $q$ & ذ & ల్ల & $\stackrel{\circ}{\circ}$ & 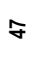 & $\check{~}$ & $\stackrel{F}{F}$ & $\stackrel{g}{q}$ & 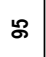 & $\tilde{\overbrace{}}$ & 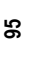 & $\tilde{q}$ & 主 & $\bar{\infty}$ & $\stackrel{8}{\approx}$ & ల్ల & ळ & $\stackrel{8}{\circ}$ & 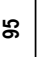 & : \\
\hline 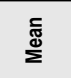 & $\begin{array}{l}0 \\
\vdots \\
\vdots \\
0 \\
0\end{array}$ & 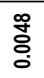 & 商 & $\begin{array}{l}0 \\
\vdots \\
0 \\
0\end{array}$ & స్̊ & 号 & 葛 & 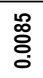 & 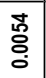 & 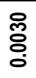 & 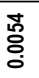 & 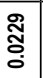 & 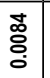 & 递 & స్ & $\begin{array}{l}\text { o. } \\
\vdots \\
0 \\
0\end{array}$ & 㙜 & $\begin{array}{l}\text { 总 } \\
\text { o. }\end{array}$ & & \\
\hline
\end{tabular}

\begin{tabular}{|c|c|c|c|c|c|c|c|c|c|c|c|c|c|c|c|c|c|c|c|c|}
\hline \multirow{3}{*}{ 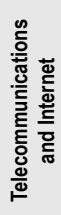 } & \multirow{2}{*}{$\begin{array}{c}\text { 옹 } \\
\underline{\underline{x}} \\
\end{array}$} & \multicolumn{3}{|c|}{ 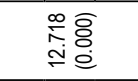 } & \multicolumn{2}{|c|}{ 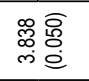 } & \multicolumn{2}{|c|}{$\begin{array}{l}\text { o. } \\
\text { co } \\
\text { ¿o. } \\
\end{array}$} & \multicolumn{3}{|c|}{ 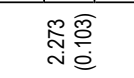 } & \multicolumn{2}{|c|}{ 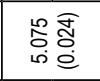 } & \multicolumn{3}{|c|}{ 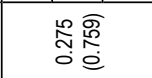 } & 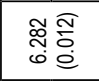 & \multicolumn{2}{|c|}{ 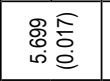 } & \\
\hline & & $\overline{\mathfrak{g}}$ & 8 & 造 & id & א & $\mathfrak{R}$ & $\bar{\Phi}$ & ⿸্ল & $\stackrel{\stackrel{\mathscr{g}}{\odot}}{\stackrel{2}{2}}$ & 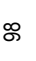 & $\stackrel{\circ}{\sim}$ & 峞 & 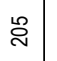 & $\stackrel{8}{8}$ & $\bar{N}$ & 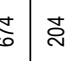 & 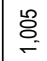 & 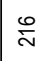 & 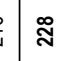 \\
\hline & 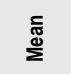 & 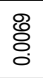 & 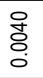 & ஜ̊g & . & $\begin{array}{l}\text { 管 } \\
0\end{array}$ & 畹 & $\begin{array}{l}\text { 怼 } \\
\stackrel{0}{0}\end{array}$ & ठू. & 訔 & 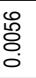 & | & 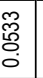 & है & \begin{tabular}{l|l} 
\\
$\vdots$ \\
$\vdots$ \\
0
\end{tabular} & & 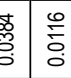 & 策 & 离 & 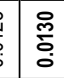 \\
\hline
\end{tabular}

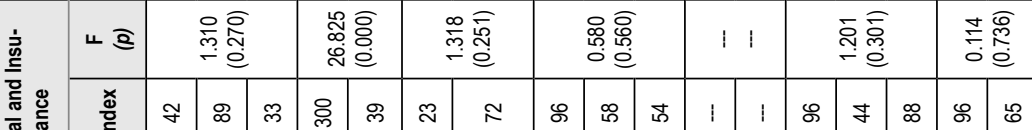

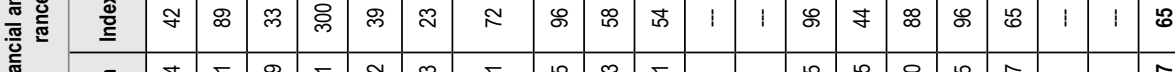

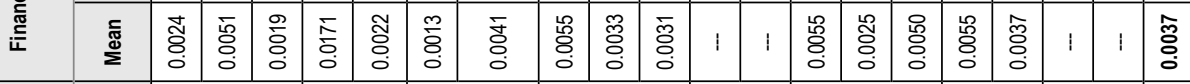

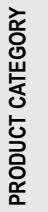

\begin{tabular}{|c|c|c|c|c|c|c|c|c|c|c|c|c|c|c|c|c|c|c|c|c|c|}
\hline \multirow{3}{*}{ 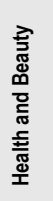 } & \multirow{2}{*}{$\begin{array}{c}4 \sqrt{\Omega} \\
\frac{\underline{x}}{\underline{\underline{c}}}\end{array}$} & \multicolumn{3}{|c|}{ 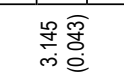 } & \multicolumn{2}{|c|}{ 총 } & \multicolumn{2}{|c|}{ 臱 } & \multicolumn{3}{|c|}{ 总高总 } & \multicolumn{2}{|c|}{11} & \multicolumn{3}{|c|}{$\begin{array}{l}\text { 용. } \\
0.00 \\
0\end{array}$} & \multicolumn{2}{|c|}{ 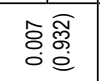 } & \multicolumn{2}{|c|}{11} & \\
\hline & & $\stackrel{\infty}{\sim}$ & $R$ & $\stackrel{\cong}{\infty}$ & $\stackrel{\circ}{\circ}$ & in & 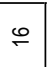 & $\bar{\infty}$ & is & $\hat{m}$ & q & i & 1 & $\mathscr{8}$ & $\ddot{8}$ & $\infty$ & $R$ & 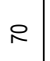 & i & 1 & $R$ \\
\hline & 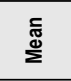 & 음 & $\begin{array}{l}\text { 웅 } \\
\text { क्. }\end{array}$ & i. & छั & $\begin{array}{l}\text { o. } \\
\text { o. } \\
\end{array}$ & ¿. & $\begin{array}{l}0 \\
0 \\
0 \\
0\end{array}$ & $\begin{array}{l}0 \\
: \\
0\end{array}$ & $\begin{array}{l}\overline{0} \\
0 \\
0\end{array}$ & ֻَّ & & 1 & $\begin{array}{l}\text { 荌 } \\
\text {. }\end{array}$ & 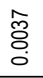 & 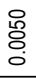 & $\begin{array}{l}0 \\
0 \\
0 \\
0\end{array}$ & $\begin{array}{l}0 \\
0 \\
0 \\
0\end{array}$ & 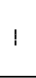 & 1 & 浐 \\
\hline
\end{tabular}

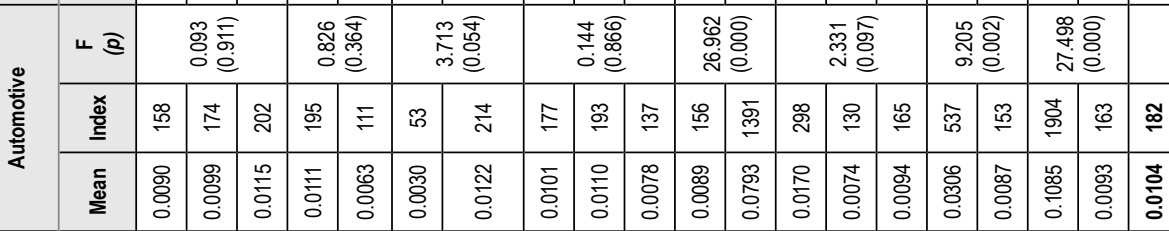

\begin{tabular}{|c|c|c|c|c|c|c|c|c|c|c|c|c|c|c|c|c|c|c|c|c|}
\hline \multirow{3}{*}{ 훈 } & $4 \sqrt{3}$ & \multicolumn{3}{|c|}{ 房愛 } & \multicolumn{2}{|c|}{ 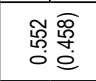 } & \multicolumn{2}{|c|}{ 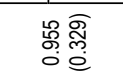 } & \multicolumn{3}{|c|}{ 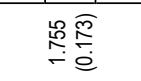 } & \multicolumn{2}{|c|}{ 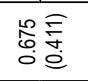 } & \multicolumn{2}{|c|}{ 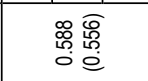 } & \multicolumn{2}{|c|}{ 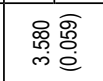 } & \multicolumn{2}{|c|}{ 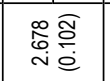 } & \\
\hline & 堿 & $\approx$ & $\approx$ & 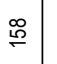 & 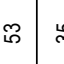 & 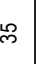 & 邑 & $\hat{f}$ & 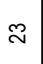 & $\bar{\sigma}$ & 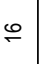 & F & $\stackrel{8}{:}$ & 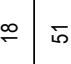 & $\infty$ & $\dddot{ஜ}$ & g) & $\stackrel{\infty}{\text { స్ }}$ & F & F \\
\hline & $\underset{\stackrel{\varpi}{\varpi}}{\Sigma}$ & \begin{tabular}{l|}
$\infty$ \\
$\vdots$ \\
0 \\
0 \\
\end{tabular} & \begin{tabular}{l|}
$\infty$ \\
\multirow{0}{0}{} \\
0 \\
0
\end{tabular} & $\begin{array}{l}8 \\
0 \\
\end{array}$ & 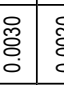 & 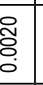 & $\stackrel{8}{\circ}$ & $\begin{array}{l}\overline{\text { ầ }} \\
\text { o. }\end{array}$ & $\begin{array}{l} \\
\\
\\
0 \\
0\end{array}$ & \begin{tabular}{l|l}
$\mathscr{0}$ \\
\\
0 \\
0
\end{tabular} & \begin{tabular}{l|l} 
\\
\\
0 \\
0
\end{tabular} & 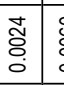 & $\begin{array}{l}0 \\
8 \\
0 \\
\end{array}$ & \begin{tabular}{l|l} 
\\
\\
\\
0
\end{tabular} & \begin{tabular}{|c|}
\multirow{2}{*}{} \\
\\
0
\end{tabular} & \begin{tabular}{|l|}
0 \\
0 \\
0 \\
0 \\
\end{tabular} & \begin{tabular}{|l|}
\multirow{2}{*}{} \\
\\
0 \\
\end{tabular} & $\begin{array}{l}\text { o. } \\
\vdots \\
\vdots \\
0\end{array}$ & \begin{tabular}{l}
\multirow{2}{*}{} \\
\\
\end{tabular} & 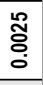 \\
\hline$\frac{\underline{m}}{3}$ & & 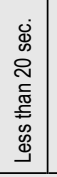 & \begin{tabular}{l|}
$\dot{s}$ \\
$\stackrel{o}{0}$ \\
$\stackrel{2}{N}$
\end{tabular} & 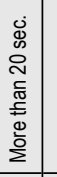 & \begin{tabular}{c|c}
$\mathbf{5}$ \\
$\underline{1}$
\end{tabular} & 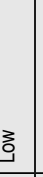 & 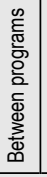 & 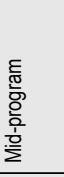 & 兮 & & 壖 & 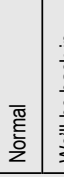 & 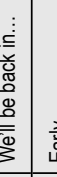 & 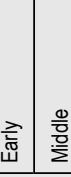 & 㸘 & 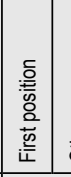 & 衰 & 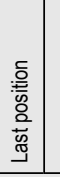 & . & \\
\hline & & 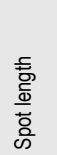 & & & 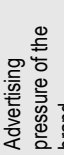 & & & & 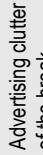 & & & 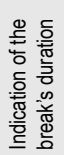 & & 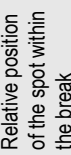 & & 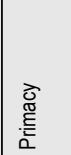 & & 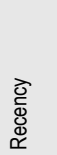 & & 愛 \\
\hline
\end{tabular}




\begin{tabular}{|c|c|c|c|c|c|c|c|c|c|c|c|c|}
\hline $\begin{array}{ll}\text { Tab. 5: } & \text { AN } \\
\text { an }\end{array}$ & ve & 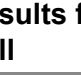 & 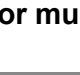 & ole & to & 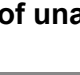 & 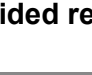 & & pr & ct & jory & \\
\hline \multirow[t]{2}{*}{ Variables } & \multicolumn{2}{|c|}{ Food } & \multicolumn{2}{|c|}{ Automotive } & \multicolumn{2}{|c|}{$\begin{array}{l}\text { Health and } \\
\text { Beauty }\end{array}$} & \multicolumn{2}{|c|}{$\begin{array}{l}\text { Financial and } \\
\text { Insurance }\end{array}$} & \multicolumn{2}{|c|}{$\begin{array}{c}\text { Telecommu- } \\
\text { nications and } \\
\text { Internet }\end{array}$} & \multicolumn{2}{|c|}{ Total } \\
\hline & $F$ & $p$ & $F$ & $p$ & $F$ & $p$ & $F$ & $p$ & $F$ & $p$ & $F$ & $p$ \\
\hline Spot length & 4.326 & 0.013 & 0.246 & 0.782 & 2.110 & 0.121 & 3.907 & 0.020 & 8.440 & 0.000 & 11.202 & 0.000 \\
\hline $\begin{array}{l}\text { Advertising } \\
\text { pressure } \\
\text { of the brand }\end{array}$ & 0.549 & 0.459 & 1.877 & 0.171 & 0.681 & 0.409 & 35.667 & 0.000 & 0.118 & 0.732 & 21.371 & 0.000 \\
\hline $\begin{array}{l}\text { Position of the } \\
\text { commercial } \\
\text { break in relation } \\
\text { to the program }\end{array}$ & 1.649 & 0.199 & 2.938 & 0.087 & 0.440 & 0.507 & 1.655 & 0.198 & 0.556 & 0.456 & 7.777 & 0.005 \\
\hline $\begin{array}{l}\text { Advertising } \\
\text { clutter of the } \\
\text { break }\end{array}$ & 2.904 & 0.055 & 0.919 & 0.399 & 2.575 & 0.076 & 0.864 & 0.422 & 1.577 & 0.207 & 1.246 & 0.288 \\
\hline $\begin{array}{l}\text { Indication of the } \\
\text { break's duration }\end{array}$ & 0.021 & 0.886 & 5.726 & 0.017 & --- & --- & --- & --- & 0.021 & 0.884 & 0.896 & 0.344 \\
\hline $\begin{array}{l}\text { Relative position } \\
\text { of spot } \\
\text { in the break }\end{array}$ & 0.973 & 0.378 & 1.509 & 0.221 & 0.169 & 0.844 & 1.946 & 0.143 & 0.295 & 0.744 & 1.180 & 0.307 \\
\hline Primacy & 1.548 & 0.214 & 1.463 & 0.226 & 0.409 & 0.522 & 0.610 & 0.435 & 0.121 & 0.728 & 2.843 & 0.092 \\
\hline Recency & 0.755 & 0.385 & 9.652 & 0.002 & --- & --- & --- & --- & 0.414 & 0.520 & 13.168 & 0.000 \\
\hline
\end{tabular}

Source: own elaboration

of these indices, where scores lower than 100 indicate that a variable had a negative effect on recall, while scores higher than 100 indicate the opposite.

When only those variables or interactions that affected unaided recall, according to the results shown in Tab. 6 , were considered, the following conclusions could be drawn based on the indices shown in Tab. 6:

- Industry influences unaided recall levels, as the results show that, on average, a brand from the "Telecommunications and Internet" industry, the industry with the highest recall level (228), would achieve five times more recall than a brand from the "Food" industry, the industry with the lowest recall level (44).

- While longer spot lengths are associated with higher levels of recall, as the use of spots lasting less than 20 seconds entailed a $54 \%$ decrease in recall, whereas the use of spots lasting more than 20 seconds entailed a $130 \%$ increase in recall, the exact variation differs depending on the industry. Thus, for example, the range of variation in unaided recall for the "Automotive" industry was 44 points (202$158)$, compared to 476 points (546-70) for the "Telecommunications and Internet" industry.
- Unaided recall of spots for brands with high advertising pressure is almost four times as high as unaided recall for brands with low advertising pressure. Again, industry plays a moderating role in this relationship, with the "Food" industry showing the least variation (18 points) and the "Financial and Insurance" industry showing the most (261 points).

- Generally speaking, spots included in commercial breaks shown mid-program generate three times as much recall as spots included in breaks between programs. However, the opposite effect was found in the "Food" industry, compared to the others, as brands in that industry achieved higher levels of recall when the spot was included in a between-programs break.

- Overall, inserting spots in low-clutter commercial breaks increased recall by $49 \%$. However, this benefit was considerably more apparent in the "Telecommunications and Internet" industry $(\Delta 267 \%)$, followed at a great distance by the "Automotive" $(\Delta 77 \%)$ and "Health and Beauty" industries $(\Delta 51 \%)$. These differences thus reflect an interaction effect of industry with the relationship between the advertising clutter of a break and recall. 


\begin{tabular}{|c|c|c|}
\hline \multirow{2}{*}{ VARIABLE } & \multicolumn{2}{|c|}{ UNAIDED RECALL } \\
\hline & $\mathbf{F}$ & $\mathbf{p}$ \\
\hline \multicolumn{3}{|l|}{ Main effects } \\
\hline Industry & 10.815 & 0.000 \\
\hline Spot length & 7.188 & 0.001 \\
\hline Advertising pressure of the brand & 14.384 & 0.000 \\
\hline Position of the commercial break in relation to the program & 6.535 & 0.011 \\
\hline Advertising clutter of the break & 1.748 & 0.174 \\
\hline Indication of the duration of the break & 0.083 & 0.773 \\
\hline Relative position of the spot in the break & 0.557 & 0.573 \\
\hline Primacy & 1.323 & 0.250 \\
\hline Recency & 4.712 & 0.030 \\
\hline \multicolumn{3}{|l|}{ Interaction effects } \\
\hline Industry $\times$ Spot length & 4.822 & 0.000 \\
\hline Industry $\times$ Advertising pressure of the brand & 3.470 & 0.008 \\
\hline Industry $x$ Position of the commercial break in relation to the program & 0.515 & 0.725 \\
\hline Industry $x$ Advertising clutter of the break & 1.933 & 0.051 \\
\hline Industry $\mathrm{x}$ Indication of the break's duration & 2.936 & 0.019 \\
\hline Industry $\mathrm{x}$ Relative position of the spot within the break & 1.049 & 0.396 \\
\hline Industry x Primacy & 0.589 & 0.671 \\
\hline Industry $x$ Recency & 4.918 & 0.002 \\
\hline
\end{tabular}

- Overall, indicating the duration of the commercial break increased recall by $302 \%$. Due to the interaction effects with industry, this variable was found to play a key role in advertising recall in the "Automotive" $(\triangle 1,291 \%)$ and "Telecommunications and Internet" $(\Delta 835 \%)$ industries.

- Finally, recency multiplied recall levels almost sevenfold, with the effect being particularly noticeable in the "Automotive" $(\Delta 1,804 \%)$ and "Telecommunications and Internet" $(\Delta 905 \%)$ industries.

\section{Conclusions and Discussion}

This paper has provided arguments for treating industry as another variable for media planning management in order to increase the advertising effectiveness of a television campaign in terms of advertising recall.

Traditionally advertising industry players have considered the industry or product category to which a brand belongs to be a criterion for deciding on a medium (product affinity with the medium or affinity between the medium's audience and the target audience). Thus, a brand's industry has only played a role in the initial media planning decisions, and its potential benefits as a key variable in the set of decisions involved in media planning, able to moderate a campaign's effectiveness, have gone untapped.

One of the main contributions of this paper is the set of industry-specific indices quantifying the variation in recall levels arising from decisions taken in relation to the different media planning variables considered. To this end, by treating industry as simply another media planning variable, advertisers can optimize their management of conventional variables (length, position, advertising pressure of the brand, etc.) to achieve maximum recall. The findings of this research thus allow 
advertisers to determine whether the television medium offers the industry to which their brand belongs greater or lesser average recall for their campaigns, compared to the other industries competing on the medium, thereby introducing a new criterion in the decision of which advertising media the advertiser should use. Industries such as the "Automotive" and "Telecommunications and Internet" industries clearly benefit from the use of television in terms of effectiveness, whereas industries such as "Food" or "Financial and Insurance" do not. This conclusion does not question the suitability of television as an advertising medium for those industries. However, this paper does show that some industries may benefit more than others from qualitative management of the media planning variables, and it points to which variables advertisers should specifically focus on to optimize the recall of their campaigns. In other words, this paper does not prove that an advertiser from the "Financial and Insurance" industry is wrong to include television in its media plan. Rather, the generic implication is that, for that industry, the increased costs of the advertising campaign that would arise from acting on the media planning variables to secure preferential positioning or increase spot length, which always entail a surcharge on the initial rates, are not worthwhile. Traditionally, media centers offer planning proposals based on objective criteria regarding the cost/improved effectiveness ratio of qualitative management of the different planning variables. The potential increases in a campaign's effectiveness are considered to be the same for all advertisers; however, in reality, the effect varies among different advertisers due to the influence of a very complex set of factors, such as the available budget for the actions, the planners' technical knowledge, or knowledge of the competition's actions with regard to television. Showing how industry influences these variables affords advertisers a new criterion to optimize and improve the planning proposals that these centers offer.

However, given that in practice the results of an advertisement's effectiveness depend on the interaction of all the media planning variables, more than on the individual effect of any one, this paper, in addition to analyzing the individual effect of each of these variables on unaided recall, also looked at their combined effect, whether direct or moderated by industry.
The results for the individual effects of the planning variables on recall were consistent with the current state of the art. However, when all the variables were analyzed together, the direct influence of the degree of advertising clutter of the commercial break, indicating the break's duration, the spot's relative position within the break, and the primacy effect on unaided recall did not occur as established by the literature. Moreover, the results also indicated that the direct effects on recall of spot length, the advertising pressure of a brand, break clutter, indication of a break's duration, and the recency effect are moderated by industry. This finding leads us to conclude that there is a need for additional research to corroborate these results and, moreover, to advance knowledge of the combined effect of all these planning variables on unaided recall with a view to optimizing television advertising management, which must go beyond mere consideration of each individual variable's effect on recall.

While advertising effectiveness depends on the industry and on its combined effect with the media planning variables, the findings presented here allow agencies and planners to offer added value to their clients: first, by providing guidelines to follow depending on the industry to which the client belongs and the planning variables; and second, by customizing the criteria used to group product categories based on the client's needs. In this context, the results of the combined analysis of all the media planning variables, shown in Tab. 4, have the following practical implications for improving recall rates by industry:

The "Financial and Insurance" industry differs from the rest in that, with the exception of a brand's advertising pressure, differentiated management of the media planning variables yields no benefit in terms of increased recall of its campaigns. It is thus important for campaigns for brands in this industry to have high advertising pressure. Although highpressure campaigns would increase recall for all the analyzed industries, the "Financial and Insurance" industry would see the greatest increase $(200 \%)$. However, because it is the industry to benefit the most from this variable (high advertising pressure multiplies recall more than sevenfold compared to low advertising pressure), and because it is the only variable that yields improvements for the industry, when planning television campaigns, its advertisers 
should consider concentrating their investments with the aim of ensuring that the volume of its campaigns' GRPs doubles the average values for the other brands advertised on this medium.

For the "Automotive" industry, media plans should clearly make securing the first and last positions in a break a goal. Placing an advertisement from the "Automotive" industry in the last position of a break yields a striking 20 times more recall than the overall average for television ( 0.1085 and 0.0057 , respectively). As the surcharges for this position increase the cost of the advertising space by approximately $30 \%$, the "Automotive" industry has the chance to increase the recall of its campaigns without proportionally increasing the cost thereof, as recall would increase by $1,804 \%$ compared to the overall recall for the medium (100). For this industry, it is also cost-effective to show advertisements in breaks whose duration is indicated to the audience. In this case, the recall of an "Automotive" industry spot placed in such a break is almost 9 times higher than the average values obtained in breaks for which the duration is not indicated. The surcharges for including advertisements in this type of break vary from network to network, and they also depend on the number of spots the break beginning with "We'll be back in..." contains. If we assume that the price increase would be between 20 and $50 \%$ of the initial rate for the spot, it will always be cost-effective for "Automotive" industry advertisers to arrange for their spots preferably to be shown in these types of breaks.

Advertisers from the "Health and Beauty" industry should bear in mind that only two planning variables will allow them to increase recall. First, for this industry, spot length is particularly decisive. Spot lengths of more than the standard 20 seconds are especially effective, as they nearly triple recall (2.6). The second variable of interest for this industry is the advertising clutter of the break in which the advertisement is shown. For brands from the "Health and Beauty" industry, relatively unsaturated commercial breaks are preferable. Recall is up to four times higher when the spots of advertisers from this industry are shown in low-cutter breaks compared to mediumclutter ones.

Advertisers from the "Telecommunications and Internet" industry can increase recall by means of five of the eight analyzed variables. Spot length affects them more than advertisers from other industries. Indeed, by increasing the lengths of their spots beyond the average 20 seconds, advertisers from the "Telecommunications and Internet" industry can boost recall almost eightfold. This industry should thus use long advertisements (30 seconds), as the increased recall makes the surcharge paid for the longer length quite cost-effective. Contracting preferential positions (first and last) in the commercial break with the networks also benefits brands from the "Telecommunications and Internet" industry. Placing a spot in the first position of a commercial break triples the recall generated by placing it elsewhere in the break, while placing it last would increase recall almost fivefold. Therefore, for these advertisers, the $30 \%$ surcharge for these preferential positions is entirely cost-effective. The fourth variable of interest to this industry would be indication of the break's duration. Negotiating with networks to have their spots included in these types of breaks would increase recall 4.3 times compared to that achieved in a conventional break. Finally, advertisers in the "Telecommunications and Internet" industry should also take the degree of advertising clutter in the break into account, although the improvements in recall achieved through differentiated management of this variable are not as dramatic, as shown by the indices in Tab. 4 (195 for medium clutter vs 367 for low clutter).

Advertisers from the "Food" industry should consider the effects of four planning variables when seeking to boost the recall of their campaigns. Brands in this industry benefit from increased spot length, as the use of durations of greater than 20 seconds yields a fivefold increase in campaign recall compared to alternatives in the industry with durations of 20 seconds or less. "Food" was the only industry of the five analyzed here for which recall increased when the commercial break was inserted between programs; in all the other industries, greater recall was achieved with mid-program breaks. Finally, this industry should also take into account preferential positions. Showing a spot first in the break increases recall fourfold, while showing it last increases it more than fivefold.

Needless to say, implementing these proposals can be complex and, in some cases, unviable, due to the factors conditioning the television advertising market in Spain. Among the conditioning factors and challenges advertisers might encounter when attempting 
to implement the proposed recommendations, attention should be called to the fact that, often, spot length is determined by the creative and advertising goals. Another variable on which it is proposed that advertisers act, namely, preferential positions, would be limited by how each network chooses to distribute its advertising across breaks (i.e., many short breaks or just a few long ones). Likewise, given that many advertisers aim to secure the first and last positions for their advertisements and the supply is thus limited, payment of a surcharge for a preferential position does not guarantee that it will be attained. At the same time, not all networks offer, as part of their sales policy, commercial breaks in which the duration of the break is indicated ("We'll be back in..."). Finally, how the insertions are distributed over the course of the programming and of the breaks themselves is decided by the networks in the traditional purchasing system for the television medium (purchase at cost $x$ GRP), making it difficult, for example, for advertisers to ensure that their spots appear in relatively unsaturated breaks or in commercial breaks broadcast between programs or in the middle thereof.

In short, this research supports the initial research proposition that the industry to which a brand belongs influences the effectiveness of television advertising campaigns in terms of recall, as significant differences were found. This finding was consistent with previously reported findings by authors such as Willke (1993) or Youn et al. (2001).

These differences point to a need to examine in greater depth the rationale for the relationship between industry and advertising recall. Willke (1993) and Lee and Lee (2011) demonstrated that the lower recall of brands belonging to the "Food" industry, compared to brands in the "Automotive" industry, is due to the greater advertising pressure of the industry as a whole and/or the fragmentation of the brands competing in it. In keeping with that argument, the results of the present study show that the two industries with the highest recall - "Automotive" and "Telecommunications and Internet" - comprise a small number of brands (38 and 29, respectively) compared to the "Food" or "Health and Beauty" industries (56 and 45 , respectively), for which lower average recall levels were obtained.

Other authors, such as Youn et al. (2001), associate advertising recall with the positive or negative motivations inherent to each product category. Thus, given that the industries with the lowest recall are, according to the classification of those authors, "utilitarian" ("Food") or "avoidance"-related ("Finance and Insurance"), and the industries with the highest recall - "Telecommunications and Internet" and "Automotive" - can be considered "hedonic," consumers' prior motivations toward each industry could plausibly explain the differences between them. In this regard, focusing on attitudes and generic motivations toward each category, Isen and Daubman (1984) found that categories that generate positive attitudes necessarily generate higher advertising recall of the brands in them.

Another factor that can condition recall is the content of the advertising messages, which can be classified into two main types, depending on whether the appeal is emotional or rational. Messages with emotional content are more frequent with "hedonic" products; because they generate positive affective reactions, they tend to have higher recall (Isen, 1989). This type of advertising aims to create an emotional bond with the viewer, which increases recall by consumers and acts as a stimulus for a cognitive or affective response (Royo-Vela, 2005). In contrast, messages with rational-informative content, more commonly used for "utilitarian" products (necessities), can hinder recall due to the need to differentiate the brand based on objective attributes (rational information about the product's qualities) (Lowrey, 2006). According to this argument, the differences in recall between industries reported in the present paper could be due, to some extent, to the primacy of the emotional content in the messages of brands in the "Automotive" and "Telecommunications" industries compared to those of brands in industries such as "Food" or "Finance and Insurance," whose content is more markedly informative.

Finally, one limitation of this paper stems from the difficulty of comparing the reported results with those reported elsewhere in the academic literature, mainly due to the lack of homogeneity of the criteria used to group products into larger categories. Additionally, the recall indices obtained are not cumulative. Future research should therefore analyze the multiple interaction effects existing in each industry, taking into account those planning variables that enable better optimization of resources. 


\section{References}

Alba, J. W., \& Chattopadhyay, A. (1986). Salience Effects in Brand Recall. Journal of Marketing Research, 23(4), 363-369. https:// doi.org/10.2307/3151812.

Assmus, G., Farley, J. U., \& Lehmann, D. (1984). How Advertising Affects Sales: MetaAnalysis of Econometric Results. Journal of Marketing Research, 21(1), 65-74. https://doi. org/10.2307/3151793.

Beerli, A., \& Martín, J. D. (1999). Técnicas de medición de la eficacia publicitaria. Barcelona: Ariel Economía.

Bensi, L., \& Giusberti, F. (2007). TraitAnxiety and Reasoning under Uncertainty. Personality and Individual Differences, 43(4), 827-838. https://doi.org/10.1016/j.paid.2007.02.007.

Brown, T. J., \& Rothschild, M. L. (1993). Reassessing the Impact of TelevisionAdvertising Clutter. Journal of Consumer Research, 20(1), 138-146. https://doi.org/10.1086/209339.

Brunel, F. F., \& Nelson, R. N. (2003). Message order effects and gender differences in advertising. Journal of Advertising Research, 43(3), 330-341. https://doi.org/10.1017/S0021849903030320.

Burke, R., \& Srull, T. K. (1988). Competitive Interference and Consumer Memory for Advertising. Journal of Consumer Research, 15(1), 55-68. https://doi.org/10.1086/209145.

Chattopadhyay, A., Nedungadi, P., \& Muthukrishnan, A. V. (2001). Category structure, brand recall, and choice. International Journal of Research in Marketing, 18(3), 191-202. https://doi.org/10.1016/S0167-8116(00)00028-8.

Chowdhury, R., Finn, A., \& Olsen, G. (2007). Investigating the Simultaneous Presentation of Advertising and Television Programming. Journal of Advertising, 36(3), 85-96. https://doi. org/10.2753/JOA0091-3367360306.

Christensen, L. B., \& Hansen, F. (2005). Share of voice/share of market and long-term advertising effects. International Journal of Advertising, 24(3), 297-320. https://doi.org/10. 1080/02650487.2005.11072927.

Danaher, P., \& Rust, R. (1994). Determining the Optimal Level of Media Spending. Journal of Advertising Research, 34(1), 28-34. https:// doi.org/10.1016/0377-2217(95)00319-3.

Draganska, M., Hartmann, W. R., \& Stanglein, G. (2014). Internet versus Television Advertising: A Brand-Building Comparison. Journal of Marketing Research, 51(5), 578-590. https://doi.org/10.1509/jmr.13.0124.

Ewing, M. T., Napoli, J., \& Du Plessis,
E. (1999). Factors Affecting the In-market Recall of Food Product Advertising. Journal of Advertising Research, 39(4), 29-38.

Ha, L., \& McCann, K. (2008). An integrated model of advertising clutter in offline and online media. International Journal of Advertising, 27(4), 569-592. https://doi.org/10.2501/ S0265048708080153.

$\mathrm{Hu}$, Y., Lodish, L. M., \& Krieger, A. M. (2007). An Analysis of Real World TV Advertising Tests: A 15-Year Update. Journal of Advertising Research, 22(5), 341-353. https:// doi.org/10.2501/S0021849907070353.

Infoadex. (2014). Estudio Infoadex de la Inversión Publicitaria en España 2014. Madrid: Infoadex.

Isen, A. M. (1989). Some Ways in Which Affect Influences Cognitive Processes: Implications for Advertising and Consumer Behavior. In P. Cafferata \& A. M. Tybout (Eds.), Cognitive and Affective Response to Advertising (pp. 3-37), Lexington, MA: Lexington Books.

Isen, A. M., \& Daubman, K. A. (1984). The influence of affect on categorization. Journal of Personality \& Social Psychology, 47(6), 1206-1217. https://doi.org/10.1037/0022-3514.47.6.1206.

Jeong, Y., Kim, Y., \& Zhao, X. (2011). Competing for consumer memory in television advertising: an empirical examination of the impacts of non-editorial clutter on brand memory in mega-event broadcasts. International Journal of Advertising, 30(4), 617-640. https://doi.org/10.2501/lJA-30-4-617-640.

Jeong, Y., Tran, H., \& Zhao, X. (2012). How Much Is Too Much the Collective Impact of Repetition and Position in Multi-Segment Sports Broadcast. Journal of Advertising Research, 52(1), 87-101. https://doi.org/10.2501/JAR-52-1-087-101.

Krugman, H. E. (1983). Television Program Interest and Commercial Interruption. Journal of Advertising Research, 21(1), 21-23.

Lee, B., \& Lee, W. (2011). The impact of product knowledge on consumer product memory and evaluation in the competitive ad context: The item-specific-relational perspective. Psychology \& marketing, 28(4), 360-387. https://doi.org/10.1002/mar.20360.

$\mathrm{Li}$, C. (2010). Primacy effect or recency effect? A long-term memory test of Super Bowl commercials. Journal of Consumer Behaviour, 9(1), 32-44. https://doi.org/10.1002/cb.291.

Lloyd, D. W., \& Clancy, K. J. (1991). CPMs versus CPMIs: Implications for media planning. Journal of Advertising Research, 31(4), 34-44. 
Lowrey, T. (2006). The Relation between Script Complexity and Commercial Memorability. Journal of Advertising, 35(3), 7-15. https://doi. org/10.2753/JOA0091-3367350301.

Martín-Santana, J. D., Reinares-Lara, P., \& Reinares-Lara, E. (2016). Spot Length and Unaided Recall in Television. Journal of Advertising Research, 56(3), 274-288. https://doi.org/10.2501/JAR-2016-035.

McDonald, C. (2000). Tracking Advertising and Monitoring Brands. Henley: Admap Publications.

Media Dynamics. (2006). How TV Commercial Awareness and Attribute Ratings Vary by Product Class. In TV Dimensions (pp. 359-361). Retrieved from http://www. mediadynamicsinc.com/uploads/2015/04/how_ tv_commercial_awareness.pdf.

Moorman, M., Neijens, P., \& Smit, E. (2007). The Effects of Program Involvement on Commercial Exposure and Recall in a Naturalistic Setting. Journal of Advertising, 36(1), 121-137. https://doi.org/10.2753/JOA0091-3367360109.

Moorman, M., Willemsen, L. M., Neijens, P., \& Smit, E. (2012). Program-Involvement Effects on Commercial Attention and Recall of Successive and Embedded Advertising. Journal of Advertising, 41(2), 25-38. https://doi. org/10.2753/JOA0091-3367410202.

Mord, M. S., \& Gilson, E. (1985). Shorter Units: Risk-Responsibility-Reward. Journal of Advertising Research, 25(4), 9-19.

Naik, N., Mantrala, M., \& Sawyer, A. (1998). Planning Media Schedules in the Presence of Dynamic Advertising Quality. Marketing Science, 17(3), 214-235. https://doi. org/10.1287/mksc.17.3.214.

Newell, S. J., \& Henderson, K. V. (1998). Super Bowl advertising: field testing the importance of advertisement frequency, length and placement on recall. Journal of Marketing Communications, 4(4), 237-248. https://doi. org/10.1080/135272698345780.

Newell, S. J., \& Wu, B. (2003). Evaluating the Significance of Placement on Recall of Advertisements during the Super Bowl. Journal of Current Issues \& Research in Advertising, 25(2), 57-67. https://doi.org/10.1080/10641734. 2003.10505149.

Newstead, K., \& Romaniuk, J. (2009). Cost per second: the relative effectiveness of 15- and 30-second television advertisements. Journal of Advertising Research, 50(1), 68-76. https://doi.org/10.2501/S0021849910091191.
Nielsen Media Research \& Cable Television Advertising Bureau. (2000). Unaided Recall Study (Phase II). Retrieved from http://www. thecab.tv/main/whyCable/studies/unaidedrecall-study.shtml.

Norris, C. E., Colman, A. M., \& Aleixo, P. A. (2003). Selective exposure to television programmes and advertising effectiveness. Applied Cognitive Psychology, 17, 593-606. https://doi.org/10.1002/acp.892.

Nyilasy, G., \& Reid, L. N. (2009). Agency practitioners' meta-theories of advertising. International Journal of Advertising, 28(4), 639-668. https://doi.org/10.2501/S0265048709200801.

Patzer, G. I. (1991). Multiple dimensions of performance for thirty second and fifteen second commercials. Journal of Advertising Research, 31, 18-25.

Pergelova, A., Prior, D., \& Rialp, J. (2010). Assessing advertising efficiency: Does the Internet Play a Role? Journal of Advertising, 39(3), 39-54. https://doi.org/10.2753/JOA00913367390303.

Pieters, R., \& Bijmolt, T. (1997). Consumer memory for television advertising: a field study of duration, serial position, and competition effects. Journal of Consumer Research: an Interdisciplinary Quarterly, 23(4), 362-372. https://doi.org/10.1086/209489.

Rachman, S. (1998). A cognitive theory of obsessions: elaborations. Behavior Research and Therapy, 36(4), 385-401. https://doi. org/10.1016/S0005-7967(97)00040-5.

Riebe, E., \& Dawes, J. (2006). Recall of radio advertising in low and high advertising clutter formats. International Journal of Advertising, 25(1), 71-86. https://doi.org/10.10 80/02650487.2006.11072952.

Romaniuk, J., Sharp, B., Paech, S., \& Driesener, V. (2004). Brand and Advertising Awareness: A Replication and Extension of a Known Empirical Generalisation. Australasian Marketing Journal, 12(3), 70-80. https://doi. org/10.1016/S1441-3582(04)70107-X.

Ross, H. L. (1982). Recall versus Persuasion: An answer. Journal of Advertising Research, 22(1), 13-17.

Rossiter, J. R., \& Bellman, S. (2005). Marketing Communications. Australia: Pearson Education.

Royo-Vela, M. (2005). Emotional and Informational Content of Commercials: Visual and auditory circumplex spaces, product information and their effects on Audience 
evaluation. Journal of Current Issues \& Research in Advertising, 27(2), 13-38. https://doi.org/10.1080/10641734.2005.10505 179.

Sethuraman, R., \& Tellis, G. J. (1991). An analysis of the tradeoff between advertising and price discounting. Journal of Marketing Research, 28(2), 160-174. https://doi.org/10.2307/3172805.

Singh, S. N., \& Cole, C. A. (1993). The Effects of Length, Content, and Repetition on Television Commercial Effectiveness. Journal of Marketing Research, 30(1), 91-104. https://doi.org/10.2307/3172516.

Smith, R. E. (1986). Principles of Positive Reinforcement and Performance Feedback. In J. M. Williams (Ed.), Applied Sport Psychology: Personal Growth to Peak Performance (pp. 35-46). Palo Alto, CA: Mayfield.

Soberman, D. (2005). The complexity of media planning today. Journal of Brand Management, 12(6), 420-429. https://doi. org/10.1057/palgrave.bm.2540237.

Stewart, D. W., \& Furse, D. H. (1985). The effects of television advertising execution on recall, comprehension and persuasion. Psychology \& Marketing, 2(3), 135-160. https://doi.org/10.1002/mar.4220020303.

Stewart, D. W., \& Koslow, S. (1989). Executional Factors and Advertising Effectiveness: A Replication. Journal of Advertising, 18(3), 21-32. https://doi.org/10.10 80/00913367.1989.10673158.

Sujan, M., \& Dekleva, C. (1987). Product Categorization and Inference Making: Some Implications for Comparative Advertising. Journal of Consumer Research, 14(3), 372-378. https://doi.org/10.1086/209120.

Swaminathan, S., \& Kent, R. (2013). Secondby Second Analysis of Advertising Exposure in TV Pods: The Dynamics of Position, Length, and Timing. Journal of Advertising Research, 53(1), 91-100. https://doi.org/10.2501/JAR-53-1-091-100.

Terry, W. S. (2005). Serial Position Effects in Recall of Television Commercials. The Journal of General Psychology, 132(2), 151-163. https://doi.org/10.3200/GENP.132.2.151-164.

Vakratsas, D., \& Ambler, T. (1999). How advertising works: What do we really know? Journal of Marketing, 63(1), 26-43. https://doi. org/10.2307/1251999.

Van den Putte, B. (2009). What matters most in advertising campaigns? The relative effect of media expenditure and message content strategy. International Journal of Advertising,
28(4), 669-690. https://doi.org/10.2501/ S0265048709200813.

Ward, S., Reibstein, D., Oliva, T. A., \& Taylor, V. (1989). Commercial Clutter: Effects of 15-Second Television Ads on Consumer Recall. In T. K. Srull (Ed.), Advances in Consumer Research. Vol. 16 (pp. 473-478.). Provo, UT, Association for Consumer Research.

Webb, P. H., \& Ray, M. L. (1979). Effects of TV clutter. Journal of Advertising Research, 19(3), 7-12.

Wells, W. D. (2000). Recognition, recall, and rating scales. Joumal of Advertising Research, 40(6), 14-20. https://doi.org/10.2501/JAR-40-6-14-20.

Wild, C. (1996). How TV campaigns work. How many exposures do people need? Rome: ESOMAR, Managing Media Data.

Willke, J. (1993). What new-product marketers should know about Related Recall. Journal of Advertising Research, 33(2), RC7-RC7.

Youn, S., Sun, T., Wells, W. D., \& Zhao, X. (2001). Commercial liking and memory: Moderating effects of product categories. Journal of Advertising Research, 41(3), 7-13. https://doi.org/10.2501/JAR-41-3-7-13.

Young, C. (2008). Why TV spot length matters. Admap, 497, 45-48.

Yu, R., Chan, A. H. S., Zhao, P., \& Gao, Y. (2012). Enhancing memorability: do remaining duration prompts affect advertising recall? International Journal of Advertising, 31(4), 861876. https://doi.org/10.2501/IJA-31-4-861-876.

Zhao, X. (1997). Clutter and serial order redefined and retested. Journal of Advertising Research, 37(5), 57-73.

Prof. Pedro Reinares-Lara, Ph.D. Universidad Rey Juan Carlos

Facultad de Ciencias Jurídicas y Sociales Department of Business Administration Spain pedro.reinares@urjc.es.

Prof. Josefa D. Martín-Santana, Ph.D. Universidad de Las Palmas de Gran Canaria Department of Business Administration Spain josefa.martin@ulpgc.es

Prof. Eva Reinares-Lara, Ph.D. Universidad Rey Juan Carlos Facultad de Ciencias Jurídicas y Sociales Department of Business Administration Spain eva.reinares@urjc.es 


\title{
Abstract
}

\section{OPTIMIZATION OF MEDIA PLANNING VARIABLES FOR TELEVISION BASED ON THE ADVERTISER'S INDUSTRY}

\author{
Pedro Reinares-Lara, Josefa D. Martín-Santana, Eva Reinares-Lara
}

Despite evidence of the influence of the industry or product category to which a brand belongs on advertising effectiveness, very few studies have analyzed the advertiser's industry as a variable influencing the advertising recall. This study aims to analyze the direct effect that the advertised brand's industry has on unaided advertising recall, as well as the moderating role it plays in the relationship between this recall and the following media planning variables: (1) spot length, (2) the advertising pressure put behind the brand, (3) the position of the commercial break in relation to the program, (4) the advertising clutter of the break (5), indication of the break's duration, (6) the spot's relative position in the break, and (7) primacy and recency effects. This study uses an innovative methodology that make it possible to measure spot recall in an environment that had been absolutely adjusted to the real conditions of a television audience. To this end, two sources of information that are usually used independently were combined: (1) audience data provided by the firm Kantar Media; and (2) data from ad-hoc computer-assisted telephone interviews (CATIs) administered to a sample of 2,000 individuals. The results suggest that the advertiser's industry should be treated as another media planning management variable that can be used to improve a television campaign's advertising effectiveness. Specifically, advertisers can use it to optimize their management of conventional variables (spot length, spot position, the brand's advertising pressure, etc.) to achieve maximum recall. Some industries may benefit more than others from qualitative management of the media planning variables. The main contribution of this study is to provide a better understanding of the state of the issue and to establish useful implications in the optimization of media planning for broadcasters, media planners, and advertisers.

Key Words: Television advertising, media planning variables, advertiser's industry, advertising recall.

JEL Classification: M3.

DOI: 10.15240/tul/001/2019-1-013 